\title{
Evaluation of Thyroid Antibodies and Thyroid Stimulating Hormone Level in Cases of Recurrent Early Pregnancy Loss
}

\author{
Galal HM${ }^{1}$, Azzam AZ ${ }^{1}$, Elmahdy $\mathbf{M}^{1 *}$, Osama $\mathrm{A}^{1}$ and Elsayed ET ${ }^{2}$ \\ 1Department of Obstetrics and Gynecology, Faculty of Medicine, Alexandria \\ University, Egypt \\ ${ }^{2}$ Department of Clinical and Chemical Pathology, Faculty of Medicine, Alexandria \\ University, Egypt
}

\section{Research Article \\ Volume 2 Issue 1}

Received Date: March 04, 2017

Published Date: March 27, 2017

*Correspondig author: Mohamed Elmahdy, Department of Obstetrics and Gynecology, Faculty of Medicine, Alexandria University, 13 gylis street off koleyetelteb street mehatetelraml, Alexandria, Egypt, Tel: 00201002413531, Email: mahdy_moh@yahoo.com

\section{Abstract}

Background: Autoimmune Thyroid Disease (AITD) is one of the most frequent causes of hypothyroidism in females during the fertile age. The prevalence of hypothyroidism in women in the reproductive age is about $2-3 \%$.

Objectives: Evaluate maternal anti-thyroid AB concentrations and TSH level in cases of recurrent miscarriage.

Patients and Methods: 400 female patients divided into two group's .Group A: 200including women with history of early recurrent pregnancy loss. Group B: 200 women with at least 2 living children and without previous recurrent early pregnancy loss. Antithyroglobulin antibodies and anti-thyroid peroxides using chemiluminescence immunoassay (Normal level up to $115 \mathrm{IU} / \mathrm{ml}$ and up to $35 \mathrm{IU} / \mathrm{ml}$ ) and TSH level using chemiluminescence immunoassay (Normal level 0,350- $2 \mathrm{IU} / \mathrm{ml}$ ) were assessed.

Results: $10.0 \%$ and $9 \%$ of cases $(n=200)$ and $3.0 \%$ and the same $3.0 \%$ of control group $(n=200)$ were positive for anti TG antibodies and anti TPO antibodies. There was no statistically significant correlation between levels of anti TG antibodies and anti TPO antibodies and RPL ( $\mathrm{p}=0.052) .19 \%$ of cases group showed abnormally high TSH level. On the other hand, $14 \%$ of control group showed high level TSH. There was no significant relation between recurrent pregnancy loss and abnormal TSH level $(\mathrm{P}=0.34)$.

Conclusions: Neither TSH nor anti thyroid antibodies (ATG OR anti TPO) showed significant difference in cases with recurrent miscarriage.

Keywords: Chemiluminescence; Antithyroglobulin; Anticardiolipin; Antithyroid

Abbreviations: AITD: Autoimmune Thyroid Disease; Tg: Anti-thyroglobulin; TSH: Thyroid Stimulating Hormone

\section{Introduction}

Miscarriage is the spontaneous loss of the conceptus before 20 weeks of gestation. Potential risk of possible miscarriage before pregnancy is diagnosed is about $30 \%$. 
In clinically detected pregnancy, it is $10-15 \%$ before $8^{\text {th }}$ week and 3\% between 8th and 20th weeks. Recurrent miscarriage is defined as occurrence of two or more consecutive spontaneous miscarriage. It occurs in 1-2\% of couples in the reproductive age group [1-4].

Recurrent miscarriage can be attributed to chromosomal anomalies, anticardiolipin antibodies and endocrine disorders such as poorly controlled diabetes mellitus, hyperprolactinaemia, thyroid diseases; and pelvic anatomic abnormalities. Recurrent miscarriage can be classified as either primary or secondary. Primary cases are women who have lost all their pregnancies, whereas secondary miscarriage cases have had at least one live born infant [5].

Autoimmune Thyroid Disease (AITD) is one of the common causes of hypothyroidism in women in the reproductive age. The prevalence of hypothyroidism in the general population of reproductive age is $2-3 \%$. Overt hypothyroidism is commonly associated with infertility, as thyroid hormones have a direct effect on granulosa cells, theca cells and oocyte maturation [6-8].

Autoimmune thyroid disorders are characterized by the presence of thyroid auto-antibodies (Abs), particularly thyroid peroxidase (TPO) auto Abs and antithymoglobulin (Tg) auto Abs. TPO is an enzyme responsible for iodination of tyrosine residues and coupling of iodinated residues to form thyroid hormones [9]. The presence of thyroid auto antibodies is relatively common in women in reproductive age. In an "unselected" population of women, the prevalence ranges from $6 \%$ to $20 \%$,being even higher in women with a history of recurrent pregnancy loss, (17-33\%),and in women with a history of subfertility, (10-31\%)in the developed world, thyroid autoimmunity is the main cause of hypothyroidism, which itself results in poor obstetric outcomes $[10,11]$.

Euthyroid women with thyroid autoimmunity are twice as likely to experience spontaneous miscarriages. This may be attributed to a generalised activation of the immune system, an increased risk of progression to subclinical hypothyroidism, or it could be due to the transplacental transfer of thyroid receptor blocking antibodies [9,12-15].

Hence, there is a need to screen for subclinical hypothyroidism and thyroid autoimmunity in pregnancy, especially in women with a history of spontaneous miscarriages. However, the management of women with recurrent miscarriage who have thyroid autoimmunity remains controversial.

The aim of this study is to evaluate the relation of maternal serum TSH and the percentage of recurrent miscarriage in cases with positive serum anti thyroid antibodies.

\section{Patients}

The study was being conducted on 200 women in the age group of 21-35 years recruited from the outpatient antenatal care clinic in El Shat by Maternity university Hospital. The study was conducted from September 2014 till October 2015.

This study has been approved by national research ethics committee and has been performed in accordance with the ethical standards as laid down in the 1964 Declaration of Helsinki and its later amendments or comparable ethical standards.

\section{Informed Consent}

"Informed consent was obtained from all individual participants included in the study."

\section{Patients were divided in two groups}

- Group A: 200 female patients with history of recurrent miscarriage.

- Group B: 200 female patients with at least 2 living children and without history of miscarriage.

\section{Inclusion Criteria}

- Patients within the reproductive age (21-35).

- women with recurrent first trimester pregnancy loss (two or more first trimester pregnancy loss) (1)

- The control group: women with at least 2 living children and without history of miscarriage.

\section{Exclusion Criteria}

- Women with known autoimmune disorders including patients with systemic lupus, antiphospholipid syndrome and anticardiolipin Antibody sero positive patients.

- Women with history of cervical incompetence or any other uterine pathology.

- Women already on treatment for thyroid dysfunction.

- Women with known chromosomal disorders.

- Women with known medical disorders as hypertension and diabetes. 


\section{Methods}

All the patients were subjected to:

1. Written informed consent

2. Detailed history taking: Personal history: age, smoking, alcohol and drug intake. Medical as hypertension and diabetes. Surgical as thyroid operation. Obstetric history: gravidity, parity and Past history of abortion including number of abortions and duration of pregnancy in each.

3. Complete general examination including:-

- General look as pallor, jaundice and tremors.

- Vital signs blood pressure pulse, temperature and respiratory rate

- Head and neck examination to exclude thyroid swelling

- Chest and cardiac examination

- Abdominal examination to exclude abdominal and pelvic tumor.

1. Ultrasound scanning to exclude any pelvic pathology.

2. Karyotyping to exclude chrmosomalanaomalies.

3. Laboratory investigations including:

a.Routin investigations:-complete blood picture, blood group, $\mathrm{RH}$ and fasting blood glucose level.

b. Special investigation:

- Antithyroglobulin antibodies (Antithyroglobulin auto antibodies) using chemiluminescence immunoassay. (Normal level up to $115 \mathrm{IU} / \mathrm{ml}$.)

- Antithyroid peroxidase antibodies using chemiluminescence immunoassay. (Normal level up to 35 IU/ml.)

- TSH level using chemiluminescence immunoassay. (Normal level 0,350-5,500Uu/ml)

\section{Results}

The study was conducted on 200 women in the reproductive age and was divided into two groups; Group A: 200 female patients with history of recurrent miscarriage and Group B: 200 female patients with at least 2 living children and without history of miscarriage.

There was no statistically significant difference between the two groups regarding age. The mean was $27.56 \pm 5.24$ in the first group and $26.97 \pm 4.23$ in the second group $(\mathrm{p}=0.382)$.

There was no statistically significant difference between the two studied groups regarding TSH level $(2.95 \pm 3.19$ and $2.50 \pm 3.17)$ in cases with RPL and control women $(\mathrm{p}=0.14)$ (Table 1$)$.

\begin{tabular}{|c|c|c|c|c|c|c|}
\hline & \multicolumn{2}{|c|}{$\begin{array}{c}\text { Cases } \\
(n=200)\end{array}$} & \multicolumn{2}{|c|}{$\begin{array}{c}\text { Control } \\
(n=200)\end{array}$} & \multirow{2}{*}{ Test of significant } & \multirow{2}{*}{$\mathbf{P}$} \\
\hline & No. & $\%$ & No. & $\%$ & & \\
\hline TSH & \multirow{2}{*}{162} & \multirow{2}{*}{162} & \multirow{2}{*}{172} & \multirow{2}{*}{172} & \multirow{3}{*}{$\chi^{2}=1.102$} & \multirow{3}{*}{${ }^{\mathrm{FE}} \mathrm{p}=0.14$} \\
\hline Normal $(\leq 3)$ & & & & & & \\
\hline Abnormal (>3) & 38 & 38 & 28 & 28 & & \\
\hline Min. - Max. & \multicolumn{2}{|c|}{$0.36-23.60$} & \multicolumn{2}{|c|}{$0.43-23.80$} & \multirow{3}{*}{$Z=1.955$} & \multirow{3}{*}{0.053} \\
\hline Mean \pm SD. & \multicolumn{2}{|c|}{$2.95 \pm 3.19$} & \multicolumn{2}{|c|}{$2.50 \pm 3.17$} & & \\
\hline Median & \multicolumn{2}{|c|}{2.40} & \multicolumn{2}{|c|}{2.04} & & \\
\hline
\end{tabular}

Table 1: Comparison between the two studied cases according to TSH.

$\chi^{2}$ : Chi square test

FE: Fisher Exact test

$\mathrm{Z}$ : Z for Mann Whitney test

In group A (cases. group) the level of Antithyroglobulin and anti TPO auto antibodies was normal in180and 182 patients and abnormal in 20 and 18 patients with a mean value of $65.81 \pm 139.0$ and $29.2 \pm 7.22$ In group B (control. group) the level of auto antibodies was similar for both ATG and ATPO. It was normal in194 patients and abnormal in 6 patients with a mean value of $42.70 \pm 140.93$ and $31.77 \pm 8.5$. There is no statistically

significant difference between the two groups regarding Antithyroglobulin auto antibodies and anti-thyroid peroxidase antibodies level $(\mathrm{p}=0.053)$ and $(\mathrm{P}=0.062)$ (Table 2). 


\begin{tabular}{|c|c|c|c|c|c|c|}
\hline & \multicolumn{2}{|c|}{$\begin{array}{c}\text { Cases } \\
(n=200)\end{array}$} & \multicolumn{2}{|c|}{$\begin{array}{c}\text { Control } \\
(n=200)\end{array}$} & \multirow{2}{*}{$\begin{array}{c}\text { Test of } \\
\text { significant }\end{array}$} & \multirow[t]{2}{*}{$\mathbf{P}$} \\
\hline & No. & $\%$ & No. & $\%$ & & \\
\hline \multicolumn{7}{|l|}{ Antithyroglobulin } \\
\hline \multirow{2}{*}{$\begin{array}{c}\text { Normal }(\leq 115) \\
\text { Abnormal }(>115)\end{array}$} & 184 & 184.0 & 196 & 196.0 & \multirow{2}{*}{$\chi^{2}=3.189$} & \multirow{2}{*}{0.053} \\
\hline & 16 & 16.0 & 4 & 4.0 & & \\
\hline \multicolumn{7}{|c|}{ Anti thyroid peroxidase } \\
\hline \multirow[b]{2}{*}{$\begin{array}{c}\text { Normal }(\leq 35) \\
\text { Abnormal }(>35)\end{array}$} & 93 & 93 & 98 & 98 & \multirow[b]{2}{*}{$\chi^{2}=3.589$} & \multirow{2}{*}{0.062} \\
\hline & 7 & 7 & 2 & 2 & & \\
\hline
\end{tabular}

Table 2: Comparison between the two studied cases according to Antithyroglobulin and Antithyroid peroxidase.

$\chi^{2}$ : Chi square test

Statistically significant at $\mathrm{p} \leq 0.05$

When cases with more than three abortions compared with cases with three or less abortions, there was no statistical significant difference as regards serum level of TSH $(2.88 \pm 2.95$ and $3.02 \pm 3.44)$ in cases with more and less than three miscarriage $(\mathrm{p}=0.722)$ (Table 3$)$. There

were no statistical significant difference between both groups as regards serum antithyroglobulin $\mathrm{AB}$ (55.05 \pm 121.39 and $76.56 \pm 155.12$ ) in cases with more and less than three miscarriage $(\mathrm{p}=0.357)$ (Table 4$)$.

\begin{tabular}{|c|c|c|c|c|}
\hline & \multicolumn{2}{|c|}{ No. of abortion } & \multirow[b]{2}{*}{$\mathbf{Z}$} & \multirow[b]{2}{*}{$\mathbf{P}$} \\
\hline & $\begin{array}{c}\leq 3 \\
(n=113)\end{array}$ & $\begin{array}{c}>3 \\
(n=87)\end{array}$ & & \\
\hline \multicolumn{5}{|l|}{ TSH } \\
\hline Min. - Max. & $0.48-20.65$ & $0.36-23.60$ & \multirow{3}{*}{0.355} & \multirow{3}{*}{0.722} \\
\hline Mean \pm SD. & $2.88 \pm 2.95$ & $3.02 \pm 3.44$ & & \\
\hline Median & 2.48 & 2.40 & & \\
\hline
\end{tabular}

Table 3: Relation between No. of abortion with TSH.

$\mathrm{Z}$ : Z for Mann Whitney test.

\begin{tabular}{|c|c|c|c|c|}
\hline & \multicolumn{2}{|c|}{ No. of abortion } & \multirow{2}{*}{$\mathbf{Z}$} & \multirow{2}{*}{$\mathbf{P}$} \\
\hline & $\begin{array}{c}\leq 3 \\
(n=113)\end{array}$ & $\begin{array}{c}>3 \\
(n=87)\end{array}$ & & \\
\hline \multicolumn{5}{|c|}{ Antithyroglobulin } \\
\hline Min. - Max. & $13.80-672.50$ & $12.87-666.10$ & \multirow{3}{*}{0.920} & \multirow{3}{*}{0.357} \\
\hline Mean \pm SD. & $55.05 \pm 121.39$ & $76.56 \pm 155.12$ & & \\
\hline Median & 26.05 & 24.80 & & \\
\hline \multicolumn{5}{|l|}{ Anti TPO } \\
\hline Min. - Max. & 12.88- 78.66 & $17-65.35$ & \multirow{3}{*}{0.873} & \multirow{3}{*}{0.264} \\
\hline Mean \pm SD & $29 \pm 20.64$ & $28.36 \pm 19.33$ & & \\
\hline Median & 22.5 & 31.5 & & \\
\hline
\end{tabular}

Table 4: Relation between No. of abortion with Antithyroglobulin.

$\mathrm{Z}$ : Z for Mann Whitney test.

\section{Discussion}

Miscarriage is the spontaneous loss of the conceptus before 20 weeks of gestation. Recurrent miscarriage, defined as occurrence of two or more consecutive spontaneous miscarriage .It occurs in $1-2 \%$ of couples attempting to get pregnancy [1-4]. 
The aim of this study was to evaluate maternal antithyroid auto antibodies (ATG and ATPO) antibodies concentration and TSH level in cases of recurrent miscarriage as there is a debate between this correlation.

The study was conducted on 400 woman in the reproductive age and were divided into two groups; Group A: 200 female patients with history of recurrent miscarriage and Group B: 200 female patients with at least 2 living children and without history of miscarriage.

In the present study there was no significant difference between serum level of TSH in the two studied groups $(2.95 \pm 3.19$ and $2.50 \pm 3.17)$ in cases with RPL and control women $(\mathrm{p}=0.14)$ respectively. Serum anti thyroglobulin and anti TPO antibodies level showed a non-significant elevation in the group with recurrent pregnancy loss than in the control group $(\mathrm{p}=0.053)$ and $(\mathrm{P}=0.062)$.

These results were in agreement with Pratt and his colleagues who failed to reach statistical significance $(p=0.2)$ when they were tried to evaluate women with recurrent abortions for the presence of thyroid Abs compared with the controls [16]. Also, Esplin and his colleagues compared the rate of thyroid auto antibodies positivity in women with recurrent abortion with controls (p> 0.05 not statistically significant) [13]. In a study conducted in the same year, no difference was found in miscarriage rates between Ab-negative and Ab-positive women ( $p=0.29)$ [17]. In addition, it was concluded that the risk of pregnancy loss in women with unexplained recurrent miscarriages is not affected by their thyroid Abs status [18].

On the other hand, the present results were not concordant with some other studies in this field. Stagnaro-Green and his colleague Glinoer were reported a doubling of the miscarriage rate in women who were positive with Antithyroid Abs compared to those with negative Abs $(p=0.011, p<0.001)$, respectively $[19,20]$. Also, Lejeune and his colleague were reported that the miscarriages are associated with Antithyroid Abs and took place early, within the first trimester of the pregnancy [21]. Several researchers reported that women with TPO Abs and/or TG Abs had a higher miscarriage rate than women who were negative for these antibodies $(\mathrm{P}<0.05)$ respectively [22-25].

In the present study, thyroid dysfunction in the form of abnormal serum TSH level, serum antithyroglobulin antibodies and anti TPO antibodies showed no correlation with the number of pregnancy loss if we compared women with more and less than 3 miscarriages. This may be supported also by what was found that thyroglobulin message is not expressed in placenta, decidua, or ovary in any stages of pregnancy [26].

In the present study, we studied antithyroid antibodies (ATG and ATPO), while there is a lot of auto antibodies which were not tested in this study and may have a role in recurrent pregnancy loss. Antithyroid antibodies are known to occur in normal, healthy population, and these auto antibodies are five times more common in women than in men. Because of prominent prevalence of antithyroid antibodies in normal women, interpreting the significance of these antibodies in women with reproductive problems remains difficult [21]. It is also suggested that the presence of thyroid auto antibodies reflects a generalized activation of the immune system particularly of $\mathrm{T}$ cells, which are ultimately responsible for the loss of the pregnancy [22]. So, the effect of this Abs seen by some studies may reflect only some sort of association due to immunological over activity. The limitations of this study were that we didn't differentiate between clinical and subclinical hypothyroidism. We didn't do a correlation between T3 and T4 levels and RPL.

In conclusion, thyroid dysfunction in the form of abnormal serum TSH level and levels of serum antithyroglobulin or ATPO antibodies had no correlation with recurrent early miscarriage or to the numbers of miscarriages.

Acknowledgement: To the clinical pathology team due to their assistance.

\section{References}

1. Practice Committee of the American Society for Reproductive Medicine (2008) Definitions of infertility and recurrent pregnancy loss. Fertility and Sterility 90(5S): S60.

2. Brigham SA, Conlon C, Farquharson RG (2009) A longitudinal study of pregnancy outcome following idiopathic recurrent miscarriage. Human Reproduction 14(11): 2868-2871.

3. Tulppala M, Palosuo T, Ramsay T, Miettinen A, Salonen R, et al. (2000) A prospective study of 63 couples with a history of recurrent spontaneous abortion: contributing factors and outcome of subsequent pregnancies. Human Reproduction 8(5): 764-770.

4. Carrington B, Sacks G, Regan L (2005) Recurrent miscarriage: pathophysiology and outcome. Current Opinion in Obstetrics \& Gynecology 17(6): 591597.

5. $\quad$ Li TC, Makris M, Tomsu M, Tuckerman E, Laird S (2002) Recurrent miscarriage: etiology, management 
and prognosis. Human Reproduction Update 8(5): 463481.

6. Poppe K, Glinoer D (2003) Thyroid autoimmunity and hypothyroidism before and during pregnancy. Human Reproduction 9(2): 149-161.

7. Klein RZ, Haddow JE, Faix ZE (1999) Prevalence of thyroid deficiency in pregnancy. Clinical Endocrinology 35(1): 41-46.

8. Wakim AN, Polizotto SL, Buffo MJ, Marrero MA, Burholt DR (1993) Thyroid hormones in human follicular fluid and thyroid hormone receptors in human granulosa cells. Fertility and Sterility 59(6): 1187-1190.

9. Twig G, Shina A, Amital H, Shoenfeld Y (2012) Pathogenesis of infertility and recurrent pregnancy loss in thyroid autoimmunity. Journal of Autoimmunity 38(2-3): 275-281.

10. Kennedy RL, Malabu UH, Jarrod G, Nigam P, Kannan K, et al. (2010) Thyroid function and pregnancy: Before, during and beyond. J Obstet Gynaecol 30(8): 774783.

11. Glinoer D, Soto MF, Bourdoux P, Lejeune B, Delange F, et al. (1991) Pregnancy in patients with mild thyroid abnormalities: maternal and neonatal repercussions. Clin Endocrinol Metab 73(2): 421-427.

12. Faussett MB, Branch DW (2000) Autoimmunity and pregnancy loss. Seminars in Reproductive Medicine 18(4): 379-392.

13. Pratt DE, Kaberlein G, Dudkiewicz A, Karande V, Gleicher N (1993) The association of antithyroid antibodies in euthyroidnon pregnant women with recurrent first trimester abortions in the next pregnancy. Fertility and Sterility 60(6): 1001-1005.

14. Glinoer D, Delange F (2000) The potential repercussions of maternal, fetal, and neonatal hypothyroxinemia on the progeny. Thyroid 10(10): 871887.

15. Kutteh WH, Yetman DL, Carr AC, Beck LA, Scott RT (1999) Increased prevalence of antithyroid antibodies identified in women with recurrent pregnancy loss but not in women undergoing assisted reproduction. Fertil Steril 71(5): 843-848.

16. Esplin MS, Branch DW, Silver R, Stagnaro-Green A (1998) Thyroid auto antibodies are not associated with recurrent pregnancy loss. Am J Obstet Gynecol 179(6 Pt 1): $1583-1586$.
17. Muller AF, Verhoeff A, Mantel MJ, Berghout A (1999) Thyroid autoimmunity and abortion: a prospective study in women undergoing in vitro fertilization. Fertil Steril 71(1): 30-34.

18. Rushworth FH, Backos M, Rai R, Chilcott IT, Baxter N, et al. (2000) Prospective pregnancy outcome in untreated recurrent miscarriers with thyroid auto antibodies. Hum Reprod 15(7): 1637-1639.

19. Stagnaro-Green A, Glinoer D (2004) Thyroid autoimmunity and the risk of miscarriage. Best Pract Res Clin Endocrinol Metab 18(2): 167-181.

20. Glinoer D (1998) Thyroid hyperfunction during pregnancy. Thyroid 8(9): 859-864.

21. Lejeune B, Grun JP, de Nayer P, Servais G, Glinoer D (1993) Antithyroid antibodies underlying thyroid abnormalities and miscarriage or pregnancy induced hypertension. Br J Obst Gynaecol 100(7): 669672.

22. Bussen SS, Steck T (1997) Thyroid antibodies and their relation to antithrombin antibodies, anticardiolipin antibodies and lupus anticoagulant in women with recurrent spontaneous abortions (antithyroid, anticardiolipin and antithrombin autoantibodies and lupus anticoagulant in habitual aborters). Eur J Obstet Gynecol Reprod Biol 74(2): 139143.

23. Iijima T, Tada H, Hidaka Y, Mitsuda N (1997) Effects of auto antibodies on the course of pregnancy and fetal growth. Obstet Gynaecol 90(3): 364-369.

24. Dendrinos S, Papasteriades C, Tarassi K, Christodoulakos G (2000) Thyroid autoimmunity in patients with recurrent spontaneous miscarriages. Gynecol Endocrinol 14(4): 270-274.

25. Negro R, Formoso G, Mangieri T, Pezzarossa A, Dazzi D, et al. (2006) Levothyroxine treatment in euthyroid pregnant women with autoimmune thyroid disease: effects on obstetrical complications. J Clin Endo Metab 91(7): 2587-2591.

26. Moravej A, Jeddi-Tehrani M, Salek-Moghaddam AR, Dokouhaki P, Ghods R, et al. (2010) Evaluation of thyroglobulin expression in murine reproductive organs during pregnancy. Am J Reprod Immunol 64(2): 97-103. 